ngôn ngữ và đo lường những người trả lời dự định theo những cách tương tự. Các nghiên cứu viên vàcác bác sĩ đã xem xét bộ câu hỏi sau khi được dịch từ tiếng Anh sang tiếng Việt và ngược lại. Quan trọng nhất là chúng tôi đã̃ tiến hành phân tích CFA cho ra kết quả dữ liệu phù hợp với mô hình tốt với độ tin cậy tốt.

Cùng với những điểm mạnh, nghiên cứu này cũng có một số hạn chế và điểm yếu. Bộ câu hỏi dùng để sàng lọc các triệu chứng rối loạn căng thẳng sau sang chấn trong vòng 2 tuần gần nhất. Tuy nhiên, đối tượng sinh viên năm cuối thực hiện công viêc hỗ trợ công tác chống dich COVID-19 trước thời điểm thu thập số liệu là 2 tháng. Vì vậy, các trải nghiệm của sinh viên được đánh giá tại thời điểm đó có thể không còn chính xác như lúc đang tham gia chống dịch.

Bảng câu hỏi đã được dịch sang phiên bản tiếng Việt để sử dụng phù hợp với người Việt Nam. Tuy nhiên, chúng tôi vẫn cần lưu ý và khắc phục những lỗi diễn đạt khi chuyển thể từ ngôn ngữ khác. Một câu hỏi bằng tiếng Anh sau khi được dịch thuật có thể mang một nghĩa không sát với câu hỏi nguyên bản. Ngoài ra, những người tham gia dịch thuật bộ câu hỏi chưa được đào tạo sâu về chuyên ngành ngôn ngữ.

Ngoài ra, cơ mẫu của nghiên cứu là một vấn đề đáng quan tâm. Cỗ mẫu của nghiên cứu là 68 sinh viên, thấp hơn nhiều so với mức 250 được khuyến cáo. Việc sử dụng một cõ̃ mẫu nhỏ đã dẫn đến việc câu hỏi số 17 sau khi dịch thuật đã bị loại bỏ trong cả 2 mô hình CFA.

\section{KẾT LUÂ̂N}

Đề tài nghiên cứu đã kiểm định bản tiếng Việt của bộ câu hỏi PSS-SR đánh giá các triệu chứng của rổi loạn căng thẳng sau sang chấn bản tự đánh giáthông qua đánh giá trên 68 sinh viên năm cuối của trường đại học $Y$ Hà Nội trong thời điểm đại dịch COVID-19. Qua phân tích dữ liệu, bô câu hỏi PSS-SR bản tiếng Viêt vẫn đánh giá được 3 thành phần: (1) nhớ lại, (2) Kích thích, (3) Lảng tránh với 17 yếu tố.

\section{TÀI LIÊU THAM KHẢO}

1. PTSD History and Overview - PTSD: National Center for PTSD.

2. Treatment (US) C for SA. [Table], PTSD Symptom Scale: Self-Report Version (MPSS-SR). Substance Abuse and Mental Health Services Administration (US); 2014

3. Falsetti SA, Resnick HS, Resick PA, Kilpatrick DG. The Modified PTSD Symptom Scale: A brief self-report measure of posttraumatic stress disorder. Behav Ther. 1993;16:161-2.

4. Hair J. Multivariate Data Analysis. Fac Publ [Internet]. 23 Tháng Hai 2009;

5. Psychometric Theory, 3rd Edition (McGraw-Hill Series in Psychology) by Jum C. Nunnally and Ira H. Bernstein

\title{
CÁC YẾU TỐ LIÊN QUAN ĐẾN TỬ VONG SAU ĐộT QUỴ THIẾU MÁU NÃO CỤC Bộ CẤP TẠI TIỀN GIANG
}

\section{TÓM TẮT}

Mở đâu: Đột quy là một trong những nguyên nhân gây tử vong hàng đầu trên toàn thế giới. Việc xác định tỷ suất tử vong và các yếu tố liên quan đển tử vong sau đột quy thiếu máu não cấp là quan trọng nhằm cải thiện việc điều trị cho bệnh nhân. Mục tiêu nghiên cứu: Xác định tỷ suất tử vong tích lũy tại thời điểm 1 năm và các yếu tố liên quan độc lập đến tử vong sau đột quy thiếu máu não cấp. Phướng pháp nghiên cứu: Nghiên cứu đoàn hệ quan sát tiến, cứu. Sứ dung ước tính Kaplan-Meier và mô hình hối quy Cox để xác định tỷ suất tử vong tích lũy và các yếu tố

*Bệnh viện Đa khoa Trung tâm Tiền Giang,

**Đại học Y dược Thành phố Hồ Chí Minh.

Chịu trách nhiệm chính: Nguyễn Văn Dũng

Email: dungbvtg@gmail.com

Ngày nhận bài: 9.3.2021

Ngày phản biện khoa học: 7.5.2021

Ngày duyệt bài: 14.5.2021

\section{Nguyễn Văn Dũng*, Cao Phi Phong**}

liên quan độc lập đến tử vong sau đột quy thiếu máu não cấp. Kết quả: Trong 2 năm, chúng tôi thu thập được 520 bệnh nhân đột quy thiếu máu não cục bộ cấp và theo dõi 1 năm. Tỷ suất tử vong tích lữy tại thời điểm 1 năm là $19,8 \%$. Các yếu tố liên quan độc lập với tử vong bao gồm tuổi lớn, tình trạng hôn nhân, rung nhĩ, đường huyết lúc nhập viện, viêm phổi và lấp mạch từ tim. Kết luận: Tỷ suất tử vong tích lũy tại thời điểm 1 năm là $19,8 \%$. Các yếu tố liên quan độc lập với tử vong là tuổi lớn, tình trạng hôn nhân, rung nhĩ, đường huyết lúc nhập viện, viêm phổi và lấp mach từ tim.

Tỉ̛ khóa: yếu tố, tử vong, liên quan đến, đột quy. thiếu máu não cấp.

\section{SUMMARY \\ FACTORS ASSOCIATED WITH MORTALTTY AFTER ACUTE ISCHEMIC STROKE IN TIEN GIANG \\ Background: Stroke is one of the leading causes of motarlity worldwide. The determination of mortality rates and factors associated with to mortality after}


acute ischemic stroke is important to improve the treatment of patients. Objectives: Determine the cumulative mortality rate at 1 year and factors independently associated with to mortality after acute ischemic stroke. Methods: Prospective, observational cohort study. Using Kaplan-Meier estimates and Cox regression models to determine cumulative mortality rate and factors independently associated with to mortality after acute ischemic stroke. Results: In 2 years, we collected 520 patients with acute ischemic stroke and followed up for 1 year. The cumulative mortality rate at 1 year was $19.8 \%$. Factors independently associated with mortality include older age, marital status, atrial fibrillation, blood glucose on admission, pneumonia, and cardioembolism. Conclusions: The cumulative mortality rate at 1 year was $19.8 \%$. Factors independently associated with mortality were older age, marital status, atrial fibrillation, blood glucose on admission, pneumonia, and cardioembolism.

Keywords: factor, motarlity, associated with, acute ischemic stroke.

\section{I. ĐĂT VẤN ĐỀ}

Đột quy là một trong những nguyên nhân gây tử vong hàng đầu trên toàn thế giới. Thật vậy, trên toàn câu có 6,6 triệu người tử vong do đột quy, trong số đó tử vong do đột quy. thiếu máu não cục bộ là 3,3 triệu người. Việc xác định tỷ suất tử vong và các yếu tố liên quan đến tử vong sau đột quy thiếu máu não cấp là quan trọng nhằm cải thiện việc điều trị cho bệnh nhân.

Trên thế giới, có nhiêu bài báo cáo về tỉ lệ tử vong và các yếu tố liên quan đến tử vong sau đột quy. thiếu máu não cấp. Ở Việt Nam, có ít nghiên cứu về vấn đề này với thời gian theo dõi là 1 năm. Xuất phát từ những lý do trên, chúng tôi tiến hành nghiên cứu đề tài " Các yếu tố liên quan đến tử vong sau đột quỵ thiếu máu não cấp tại Tiền Giang" với các mục tiêu sau:

- Xác đinh tỷ suất tử vong tích lũy tại thời điểm 1 năm sau đột quy thiếu máu não.

- Xác định các yếu tố liên quan độc lập với tử vong sau đột quy thiếu máu não cấp.

\section{II. ĐỐI TƯợNG VÀ PHƯƠNG PHÁP NGHIÊN CỨU}

Đôii tượng nghiên cứu: Đó là những bệnh nhân đột quy thiếu máu não cục bộ cấp nhập vào khoa Nội Thần Kinh, bệnh viện ĐKTT Tiền Giang từ tháng 02 năm 2016 đến tháng 7 năm 2017 có đủ tiêu chuẩn chọn mẫu.

Tiêu chuẩn chọn mẫu: Bệnh nhân được chẩn đoán xác định là đột quy thiếu máu nã̃o cục bộ cấp theo tiêu chuẩn lầm sàng của Tổ chức $Y$ tế Thế giới và hình ảnh chụp cắt lớp vi tính/cộng hưởng từ sọ não, đồng thời có địa chỉ rõ ràng và/hoặc số điện thoại.

\section{Tiêu chuẩn loại ra:}

- Bệnh nhân có tiền sử đột quỵ nhưng lần này nhập viện điều trị vì bệnh khác.

- Bệnh nhân không làm đầy đủ các cận lâm sàng cần thiết.

- Bệnh nhân chấn thương hoặc phẫu thuật trong vòng 3 ngày trước khi đột quy khởi phát, bệnh gan mức độ nặng, bệnh nhiếm khuẩn cấp lúc nhâp viên.

- Bệnh nhân không đồng ý tham gia nghiên cứu.

\section{Phương pháp nghiên cứu:}

Thiết kế nghiên cứu:Nghiên cứu đoàn hệ quan sát, tiến cứu.

Phương pháp chọn mẫu: Chọn liên tiếp những bệnh nhân được chẩn đoán là đột quy. thiếu máu não cấp vào khoa Nôi Thần Kinh bệnh viện ĐKTT Tiền Giang trong thời gian nghiên cứu và phải đảm bảo cõ̃ mẫu tối thiểu cho nghiên cứu.

Cõ̃ mẫu: Được tính theo công thức dành cho nghiên cứu đoàn hệ, tiến cứu có sử dụng phương pháp phân tích sống còn.

Phương pháp thu thập số liệu:

- Thu thập thông tin khi bệnh nhân nhập viện: Những bệnh nhân đột quỵ thiếu máu não cấp được khám lâm sàng tỉ mỉ và cho làm đây đủ các cận lâm sàng cần thiết để thu thập các thông tin cho nghiên cứu. Đồng thời, ghi nhận số điện thoại của bệnh nhân và người nhà bệnh nhân.

- Chúng tôi tiến hành theo dõi ngay lúc bệnh nhân còn nằm viện.

- Sau khi ra viện: chúng tôi tiếp tục theo dõi bênh nhân thông qua khám trực tiếp hoặc gọi điện thoại cho đến khi kết thúc nghiên cứu. Thời gian theo dõi sau ra viện là 1 năm.

Phương pháp xử lý số liệu: Số liệu được nhập, mã hóa và xử lý bằng phẩn mềm thống kê SPSS 20.0. Ước tính Kaplan-Meier và mô hình hồi quy Cox được sử dụng để tính tỷ suất tử vong tích lũy tại thời điểm 1 năm và xác định các yếu tố liên quan độc lập với tử vong sau đột quy. thiếu máu não cấp.

\section{KẾT QUẢ NGHIÊN CỨU}

3.1 Đặc điểm chung của mẫu nghiên cứu

Các yếu tố về dân số học. Qua 2 năm, chúng tôi thu thập được 520 bệnh nhân thỏa tiêu chuẩn chọn mấu. Trong đó, tỉ lệ nam giới và nữ giới gần bằng nhau. Tuổi trung bình của các bệnh nhân là $69 \pm 12,5$ với tuổi nhỏ nhất là 26 và tuổi lớn nhất là 96 , trong đó gần $2 / 3$ bệnh nhân thuộc nhóm tuổi $\geq 65$. Gần $3 / 4$ số bệnh nhân trong nghiên cứu sống ở khu vực nổng thôn và chỉ có $1 / 4$ số bệnh nhân trong nghiên cứu của chúng tôi có trình độ trên tiểu học. 
3.2 Một số đặc điểm liên quan đến quá trình theo dõi

Bảng 1: Một số đặc điểm liên quan đến quá trinh theo dối

\begin{tabular}{|c|c|}
\hline Một số đặc điểm & $\begin{array}{c}\text { Tân số } \\
(\mathrm{n}=520)\end{array}$ \\
\hline Tổng số bệnh nhân được theo dõi & 520 \\
\hline
\end{tabular}

Số bệnh nhân tử vong (mọi nguyên nhân)

Số bệnh nhân mất theo dõi

Thời gian theo dõi (năm)

Tỉ suất tử vong tích lũy tai tời điểm 1 năm sau đột quy thiếu máu não cấp là 19,8\%

\subsection{Kết quả phân tích đơn biến}

\begin{tabular}{|c|c|c|c|}
\hline Yếu tố nguy cớ & HR & KTC 95\% & Giá trị p \\
\hline Tuối $\geq 65$ & 3,91 & $1,90-8,05$ & $<0,001$ \\
\hline Giới nữ & 1,79 & $1,20-2,66$ & 0,004 \\
\hline Trình độ học vấn < 6 năm (tiểu học trở xuống) & 1,76 & $1,06-2,93$ & 0,029 \\
\hline Tình trang hôn nhân (ly thân, ly hôn, chồng/vơ mất) & 2,77 & $1,85-4,13$ & $<0,001$ \\
\hline Tiền sử tăng huyết áp & 1,01 & $0,67-1,51$ & 0,977 \\
\hline Tiền sử đái tháo đường & 1,16 & $0,69-1,95$ & 0,574 \\
\hline Tiền sử đột quy./TIA & 1,12 & $0,73-1,72$ & 0,610 \\
\hline Tiền sử gia đình có người thân bị đột quy. & 0,81 & $0,49-1,34$ & 0,408 \\
\hline Tiền sử nhồi máu cơ tim & 2,21 & $1,12-4,39$ & 0,023 \\
\hline Tăng huyết áp & 0,99 & $0,62-1,58$ & 0,948 \\
\hline Đái tháo đường & 0.85 & $0,53-1,37$ & 0,509 \\
\hline Rối loạn lipid máu & 0,86 & $0,57-1,29$ & 0,464 \\
\hline Rung nhĩ & 3,07 & $1,97-4,80$ & $<0,001$ \\
\hline Suy tim & 3,34 & $1,83-6,10$ & $<0,001$ \\
\hline Hút thuốc lá & 0,70 & $0,44-1,11$ & 0,131 \\
\hline Uống rượu & 0,71 & $0,43-1,14$ & 0,154 \\
\hline
\end{tabular}

Bảng 3: Các yếu tố lâm sàng

\begin{tabular}{|c|c|c|c|}
\hline Yếu tố nguy cơ & HR & KTC 95\% & Giá trị p \\
\hline HA tâm thu lúc nhập viện $\geq 140 \mathrm{mmHg}$ & 0,96 & $0,64-1,43$ & 0,832 \\
\hline HA tâm trương lúc nhập viện $\geq 90 \mathrm{mmHg}$ & 1,31 & $0,89-1,94$ & 0,174 \\
\hline Điểm Glasgow lúc nhập viện $\leq 8$ & 3,99 & $2,23-7,14$ & $<0,001$ \\
\hline Điểm NIHSS lúc nhập viện $\geq 15$ & 2,76 & $1,67-4,57$ & $<0,001$ \\
\hline Đường huyết lúc nhậ̣ viện & 1,05 & $1,01-1,10$ & 0,018 \\
\hline ĐQTMNCB tuâan hoàn sau & 1,50 & $0,99-2,29$ & 0,059 \\
\hline Viêm phối lúc nằm viện & 3,62 & $2,46-5,34$ & $<0,001$ \\
\hline Co giật lúc nằm viện & 1,28 & $0,32-5,19$ & 0,729 \\
\hline Điếm Rankin hiệu chînh lúc ra viện $>2$ & 0,71 & $0,47-1,09$ & 0,109 \\
\hline Phân nhóm nguyên nhân TOAST (Lấp mạch tữ tim) & 3,28 & $1,92-5,60$ & $<0,001$ \\
\hline
\end{tabular}

Qua phân tích hồi quy Cox đơn biến, có 12 biến số có ý nghĩa thồng kê $(p<0,05)$ và 1 biến số gân có ý nghĩa thống kê $(P<0,1)$. Các biến số này tiếp tục được đưa vào phân tích hồi quy Cox đa biến.

Kết quả phân tích đa biến

Bảng 4: Kết quả phân tích hồi quy Cox đa biến

\begin{tabular}{|c|c|c|c|}
\hline Yếu tố nguy cơ & HR & KTC 95\% & Giá trị p \\
\hline Tuối $\geq 65$ & 1,99 & $1,10-3,60$ & 0,023 \\
\hline Giới tính & 0,94 & $0,58-1,52$ & 0,794 \\
\hline Trình độ học vấn & 0,85 & $0,48-1,52$ & 0,589 \\
\hline Tình trạng hôn nhân (ly thân, ly hôn, chồng/vợ mất) & 2,15 & $1,34-3,46$ & 0,002 \\
\hline Tiền sứ nhồi máu cơ tim & 1,77 & $0,85-3,69$ & 0,130 \\
\hline Rung nhĩ & 1,70 & $1,02-2,81$ & 0,042 \\
\hline Suy tim & 1,55 & $0,78-3,07$ & 0,212 \\
\hline Điếm Glasgow lúc nhập viện & 1,16 & $0,60-2,26$ & 0,666 \\
\hline Dường huyết lúc nhập viện & 1,06 & $1,01-1,11$ & 0,030 \\
\hline Đột quyy tuần hoàn sau & 1,50 & $0,97-2,31$ & 0,069 \\
\hline Viêm phối & 2,49 & $1,61-3,86$ & $<0,001$ \\
\hline
\end{tabular}




\begin{tabular}{|c|c|c|c|}
\hline Eiếm NIHSS lúc nhập viện: 0 đến 4 & 1 & $0,52-1,38$ & Tham chiếu \\
5 đến 14 & 0,85 & $0,79-2,50$ & 0,512 \\
$\geq 15$ & 1,41 & & \\
\hline Phân nhóm nguyên theo TOAST: Bệnh mạch máu nhỏ & 1 & & \\
Lấp mạch từ tim & 2,11 & $1,18-3,79$ & Tham chiếu \\
Xơ vữa động mạch lớn & 1,02 & $0,51-2,04$ & 0,946 \\
Nguyên nhân khác/CRNN & 1,09 & $0,67-1,78$ & 0,740 \\
\hline
\end{tabular}

\section{BÀN LUÂN}

Tỉ suất tử vong tích lũy sau đột quy. thiếu máu não cấp tại thời điểm 1 năm. Trong nghiên cứu của chúng tôi, tỉ suất tử vong tích Iũy tại thời điểm 1 năm là $19,8 \%$. Kết quả này cao hơn so với một số nghiên cứu khác. Điển hình, nghiên cứu của Waje-Andreassen và cộng sự thì tỉ lệ này là $5,2 \%$. Tương tự, nghiên cứu của Putaala và cộng sự thì con số này là 4,7\%[7]. Sở dĩ có sự chênh lệch như vậy là do trong hai nghiên cứu này, dân số chọn mẫu là những bệnh nhân đột quỵ thiếu máu não tuổi còn trẻ từ 15-49, có ít bệnh lý đi kèm. Nhưng cũng có nghiên cứu cho thấy tỉ lệ này cao hơn của chúng tôi, lên đến $36,5 \%$ tại thời điểm 1 năm. Bên cạnh, nghiên cứu của Saposnik và cộng sự thể hiện tî lệ tử vong tại thời điểm 1 năm là $23,6 \%$ [8]. Tuy nhiên có nhiều nghiên cứu cho thấy tỉ lệ tử vong sau đột quỵ thiếu máu não tại thời điểm 1 năm tương đồng với nghiên cứu của chúng tôi. Điều này cho thãy tỉ lệ tử vong sau đột quy thiếu máu não còn khá cao, cần có những chiến lược phòng ngừa và điều trị hợp lý trước, trong và sau khi đột quy xảy ra.

\section{Một số yếu tố liên quan đến tử vong sau đột quy thiếu máu não cấp}

Tuổi: Trong nghiên cứu của chúng tôi, tuổi $\geq$ 65 làm tăng nguy cơ đột quỵ tái phát với $\mathrm{HR}=$ 1,$99 ; p=0,023$. Kết quả này tương tự với kết quả của những nghiên cứu khác. Điển hình, nghiên cứu của Putaala và cộng sự thấy rằng tuổi lớn liên quan độc lập với tử vong với HR = 1,07; $p=0.021$. Hớn nữa, nghiên cứu của Heuschmann và cộng sự cho thấy tuổi lớn là yếu tố liên quan độc lập với nguy cơ tử vong tử vong $(p<0,001)$. Ngoài ra, nghiên cứu của Nedeltchev và cộng sự cũng cho rằng tuổi lớn liên quan độc lập với nguy cơ tử vong với $\mathrm{HR}=1,12 ; \mathrm{p}<$ $0,001)[5]$.

Giơoi tính: Trong nghiên cứu này, giới tính không có liên quan độc lập với nguy cơ tử vong sau đột quy thiếu máu não. Mối liên quan giữa giới tính với nguy cơ tử vong cũng chưa đồng nhất trong nhiều nghiên cứu. Chẳng hạn, nghiên cứu Chang và cộng sự thì cho rằng nam giới có liên quan đến nguy cơ tử vong với $\mathrm{OR}=3,18$; $p=0,036[1]$. Bên cạnh, nghiên cứu của Adoukonou và cộng sự cũng thây rằng nam giới làm tăng nguy cơ tử vong với $\mathrm{HR}=2,3 ; \mathrm{p}=$ 0,015 . Tuy nhiên, vài nghiên cứu mới báo cáo kết cục đột quỵ xấu hơn ở nữ giới và chỉ ra rằng do nữ đến khoa cấp cứu trễ hơn nam giới và vì vậy ít nhận được liệu pháp tiêu sợi huyết, lipid và những phương pháp can thiệp và chẩn đoán khác, và thường khởi phát nặng nề hơn, dễ nhiễm trùng tiểu hơn.

Tình trạng hôn nhân: Nghiên cứu của chúng tôi cho thấy tình trạng hôn nhân có liên quan độc lập với tử vong sau đột quy thiếu máu não với $H R=2,15, p=0,002$. Kết quả này tương tự với nghiên cứu của Waje-Andreassen và cộng sự. Trong nghiên cứu này, tác giả cho thấy những bệnh nhân sống một mình sẽ tăng nguy cơ tử vong sau đột quỵ thiếu máu não với $\mathrm{HR}=3.5, \mathrm{p}=0,04$. Lý giải về điều này, tác giả thấy rằng trong mẫu nghiên cứu này, phần lớn bệnh nhân sống một mình uống rượu nhiều, trầm cảm cũng liên quan đến tình trạng hôn nhân của họ.

Tiền sử đột quy./TIA: Trong nghiên cứu này, tiền sử đột quy/TIA không có mối liên quan độc lập với nguy cơ tử vong. Kết quả này trái ngược với nghiên cứu của Chaudhary và cộng sự. Trong nghiên cứu này, tác giả cho thấy tiền sử đột quy làm tăng nguy cơ tử vong với $\mathrm{HR}=$ 1.28 và $p=0.004$ [2]. Thêm vào đó, nghiên cứu của Heuschmann và cộng sự cũng có kết quả không giống của chúng tôi.

Mức độ nặng lúc nhập viện (đánh giá bằng thang điểm NIHSS): Trong nghiên cứu của chúng tôi, mức độ nặng lúc nhập viện không có liên quan với tử vong sau đột quỵ thiếu máu não, dù trước đó trong phân tích đợn biến, yếu tố này làm tăng nguy cơ tử vong với $\mathrm{HR}=2,76$; $p<0,001$. Kết quả nghiên cứu này không giống với một số nghiên cứu khác. Điển hình, nghiên cứu của Nedeltchev và cộng sự cho rằng điểm NIHSS cao lúc nhập viện làm tăng nguy cơ tử vong với $H R=1,15 ; p=0,002$. Hơn nữa, nghiên cứu của Adoukonou và cộng sự cũng cho rằng điểm NIHSS lúc nhập viện có liên quan độc lập với nguy cơ tử vong với $\mathrm{HR}=1,1 ; \mathrm{p}=0,006$. Tuy nhiên, nguy cơ này cũng không cao do giá 
trị của HR chỉ mới vượt qua ngưỡng 1.

Đột quy tuân hoàn sau: Kết quả từ nghiên cứu của chúng tôi cho thãy đột quy. tuần hoàn sau không có mối liên quan độc lập với nguy cơ tử vong sau đột quy. Kết quả này không phù hợp với nghiên cứu của tác giả Chang và cộng sự. Trong nghiên cứu này, nhóm tác giả thây rẳng đột quy tuần hoàn sau là yếu tố tiên lượng tử vong với $\mathrm{OR}=5,25 ; \mathrm{p}=0,001[1]$. Tuy nhiên, theo tác giả Koton và cộng sự thì không phải nhồi máu não tuần hoàn sau mà chính nhồi máu não tuần hoàn trước mới làm tăng mạnh nguy cơ tử vong với $\mathrm{HR}=4,9 ; \mathrm{p}=0006$.

Tăng huyết áp: Trong nghiên cứu này, tăng huyết áp không có mối liên quan độc lập với nguy cơ tử vong. Kết quả này không tương đồng với nghiên cứu của Zou và cộng sự. Trong nghiên cứu này, tác giả nhận thấy ở những bệnh nhân lớn tuổi thì tăng huyết áp làm tăng nguy cơ tử vong sau đột quy thiếu máu não với $R R=$ 2,$56 ; p=0,024$. Mối quan hệ giữa tăng huyết áp và tử vong sau đột quy là mối quan hệ tuyến tính, nghĩa là huyểt áp càng cao thì nguy cơ tử vong do đột quy càng cao. Tuy nhiên, điều trị tăng huyết áp trong đột quỵ thiếu máu não cấp vẫn còn một số vấn đề, với những vấn đề đặt ra như khi nào sẽ khởi đầu dùng thuốc điều trị tăng huyết áp, giảm huyết áp tới mức nào, và thuốc nào nên sử dụng.

Đái tháo đường: Nghiên cứu của chúng tôi cho thấy đái tháo đường không có liên quan độc lập với tử vong sau đột quy. Điêu này không phù hợp với kết quả của vài nghiên cứu. Thật vậy, nghiên cứu của Putaala và cộng sự thấy rẳng đái tháo đường làm tăng nguy cơ tử vong với $\mathrm{HR}=$ 3,$25 ; p=0.022$ [7]. Đái tháo đường làm tăng nguy cơ tử vong có thể do bệnh lý đi kèm có trước của bệnh nhân đái tháo đường nhiều hơn, cũng như sự hủy hoại tế bào thần kinh cao hơn ở mô thiếu máu não trong tăng đường huyết..

Rung nhĩ: Trong nghiên cứu của chúng tôi, rung nhĩ có liên quan độc lập với nguy cơ tử vong sau đột quy thiếu máu não với $\mathrm{HR}=1,70$; $p=0,042$. Kết quả này phù hợp với phần lớn những nghiên cứu khác. Điển hình, nghiên cứu của Chaudhary và cộng sự thây rằng rung nhĩ liên quan độc lập với nguy cơ tử vong với $\mathrm{HR}=$ 1,33; $\mathrm{p}<0,001$ [2]. Bên cạnh, nghiên cứu của Heuschmann và cộng sự cũng cho rằng rung nhĩ làm tăng nguy cơ tứ vong tại thời điểm 1 năm. Rung nhĩ là rối loạn nhịp tim mãn tính thường thây, nhất ở những người lớn tuổi, và có ảnh hưởng đến tiên lượng đột quy.

Suy tim: Nghiên cứu của chúng tôi cho thây suy tim là một trong những yếu tố làm tăng nguy cơ tử vong sau đột quy thiếu máu não trong xử lý đơn biến với $H R=3,34 ; p<0,001$. Tuy nhiên khi đưa vào xử lý đa biến thì mối liên quan này mất đi. Suy tim là yếu tố liên quan độc lập đến tử vong sau đột quy thiếu máu não trong nhiều nghiên cứu. Điển hình, nghiên cứu Putaala và cộng sự cho thấy suy tim làm tăng nguy cơ tử vong với $H R=6,83 ; p=0,001$ [7]. Bên cạnh, nghiên cứu của Chaudhary và cộng sự cũng nhận thây suy tim là yếu tố tiên lượng độc lập với tử vong sau 1 năm đột quy thiếu máu nã̃o [2].

Viêm phổi: Đây là yếu tố được quan tâm nhiều trong các nghiên cứu về tử vong sau đột quy. Trong nghiên cứu của chúng tôi, viêm phổi trong lúc nằm viện là yếu tố có liên quan độc lập với tử vong sau đột quy. với $H R=2,49 ; p$ $<0,001$. Kết quả nghiên cứu của chúng tôi tương đồng với những nghiên cứu khác. Trước nhất, nghiên cứu của Liu và cộng sự thể hiện rằng viêm phổi có liên quan độc lập với tử vong sau đột quy. với $O R=6,95 ; p=0,003$ [4]. Kế đến, nghiên cứu của Dabilgou và cộng sự cũng cho thây viêm phổi sau đột quy liên quan độc lập với tử vong với $p<0,001$ [3]. Mặt khác, trong một nghiên cứu đoàn hệ đa trung tâm với 8.251 bệnh nhân cho thấy viêm phổi làm tăng tỉ lệ tử vong lên 2,2 lần tại thời điểm 30 ngày và 3 lần tại thời điểm 1 năm.

Đường huyết lúc nhập viên: Trong nghiên cứu của chúng tôi, đường huyết lúc nhập viện là yếu tố nguy cơ có liên quan độc lập với nguy cơ tử vong sau đột quy thiếu máu não với $H R=$ 1,$06 ; p=0,030$. Tương tự với kết quả của chúng tôi, nghiên cứu của Koton và công sự thây rằng đường huyết có liên quan với tử vong sau đột quy với $H R=1,003 ; p=0,03$. Trong nghiên cứu ở miền Bắc Manhattan, mức glucose lúc nhập viện trên 140 mg\% kết hợp với một tỉ lệ tử vong tăng, độc lập với kích thước hay độ trầm trọng của đột quỵ thiếu máu não.

Phân nhóm nguyên nhân đột quy theo TOAST: Trong nghiên cứu của chúng tôi, lấp mạch từ tim có mối liên quan độc lập với nguy cơ tử vong với $\mathrm{HR}=2,11 ; \mathrm{p}=0,012$. Kết quả này phù hợp với kết quả nhiều nghiên cứu khác. Trong nghiên cứu ở Rochester, tỉ lệ tử vong đối với những trường hợp đột quy do lấp mạch từ tim tại thời điểm 1 tháng là 30,3\%, 1 năm là $53 \%$ và 2 năm là $61,4 \%$, tî lệ này cao hơn những nghiên cứu đoàn hệ khác đã được báo cáo [6]. Mặt khác, trong nghiên cứu $\mathrm{CHS}$, phân nhóm đột quy mà gây tử vong nhiều nhất là do lấp mạch từ tim. 


\section{KẾT LUẬN}

Sau đôt quy thiếu máu não cấp, tỉ suất tử vong tích lũy tại thời điểm 1 năm là 19,8\%. Các yếu tố liên quan độc lập với tử vong sau đột quy thiếu máu não cấp bao gồm tuổi lớn, tình trạng hôn nhân (ly thân, ly hôn, chồng/vợ mất), rung nhĩ, đường huyết lúc nhập viện, viêm phổi và lấp mạch từ tim.

\section{TÀI LIỆ THAM KHẢO}

1. K. C. Chang, M. C. Tseng, T. Y. Tan, et al.(2006),"Predicting 3-month mortality among patients hospitalized for first-ever acute ischemic stroke", J Formos Med Assoc. 105(4), pp. 310-7.

2. D. Chaudhary, A. Khan, S. Shahjouei, et al.(2021),"Trends in ischemic stroke outcomes in a rural population in the United States", J Neurol Sci. 422, pp. 117339.

3. A. A. Dabilgou, A. Dravé, J. M. A. Kyelem, et al.(2020),"Frequency and Mortality Risk Factors of Acute Ischemic Stroke in Emergency
Department in Burkina Faso", Stroke Res Treat. 2020, pp. 9745206.

4. Z. Liu, W. Lin, Q. Lu, et al.(2020),"Risk factors affecting the 1-year outcomes of minor ischemic stroke: results from Xi'an stroke registry study of China", BMC Neurol. 20(1), pp. 379.

5. K. Nedeltchev, N. Renz, A. Karameshev, et al.(2010),"Predictors of early mortality after acute ischaemic stroke", Swiss Med Wkly. 140(1718), pp. 254-9.

6. G. W. Petty, R. D. Brown, Jr., J. P. Whisnant, et al.(2000),"Ischemic stroke subtypes : a population-based study of functional outcome, survival, and recurrence", Stroke. 31(5), pp. 1062-8.

7. J. Putaala, S. Curtze, S. Hiltunen, et al.(2009),"Causes of death and predictors of 5year mortality in young adults after first-ever ischemic stroke: the Helsinki Young Stroke Registry", Stroke. 40(8), pp. 2698-703.

8. G. Saposnik, M. D. Hill, M. O'Donnell, et al.(2008),"Variables associated with 7-day, 30day, and 1-year fatality after ischemic stroke", Stroke. 39(8), pp. 2318-24.

\section{CÁC YẾU TỐ LIÊN QUAN ĐẾN BIẾN ĐỔI HUYẾT ÁP TRONG QUÁ TRÌNH LOQC MÁU Ở BỆNH NHÂN BỆNH THÂ̂N MẠN GIAI ĐOẠN CUỐI CHẠY THẦn NHÂN TẠO CHU KỲ}

\section{TÓM TẮT}

Mục tiêu nghiên cứu: Nghiên cứu một số yếu tố liên quan đến biến đổi huyết áp trong quá trình lọc máu ở bệnh nhân bệnh thận mạn giai đoạn cuối chạy thận nhẩn tạo chu k̀̀y. Phương pháp nghiên cứu: nghiên cứu mô tả cắt ngang được thực hiện trên 119 bềnh nhân đang chay thận nhân tao chu kỳ̀ tai Bệnh viện đa khoa 115 Nghệ An. Kết quả: Qua nghiên cứu 714 ca lọc ở 119 bệnh nhân cho thấy: (1) 20,2\% ca lọc máu có tăng huyết áp và $15,8 \%$ ca lọc có hạ huyết áp; (2) Nhóm bệnh nhân trên 50 tuổi, tỷ lệ hạ huyết áp là $57,5 \%$ và tỷ lệ tăng huyết áp là $57,3 \%$ cao hơn nhóm bệnh nhân < 50 tuổi; nhóm bệnh nhân tăng trên $3 \mathrm{~kg}$ giữa 2 lần lọc máu có tỷ lệ hạ huyết áp cao nhất là 53,9\%; nhóm bệnh nhân chạy thận nhân tạo tốc độ siêu lọc $>750 \mathrm{ml} / \mathrm{h}$, có nồng độ ure, creatinin máu cao, albumin máu thấp có nguy cơ bị hạ huyết áp trong khi lọc máu cao hơn. Sự khác biệt có ý nghĩa thống kê với $p<0,05$. Kết luận: Sự biến đối huyết áp trong quá trình lọc máu ở bệnh nhân bệnh thận mạn giai đoạn cuối chạy thận nhẩn tạo chu kỳ có liển quan đến các yếu tố: tuổi $>50$, trọng lượng cơ thể tăng trên 3 kg giữa 2 lần lọc máu, tốc độ siêu lọc,

*Trường Đại Học Y Khoa Vinh

Chịu trách nhiệm chính: Nguyễn Văn Tuấn

Email: tuanminh1976@gmail.com

Ngày nhận bài: 9.3.2021

Ngày phản biện khoa học: 7.5.2021

Ngày duyệt bài: 12.5.2021

\section{Nguyễn Văn Tuấn, Hoàng Thị Hoài}

nồng độ ure, creatinin máu cao và nồng độ albumin máu thẩp.

Tư khóa: Biến đổi huyết áp; chạy thận nhân tạo chu kỳ.

\section{SUMMARY \\ THE FACTORS RELATED TO CHANGERS OF BLOOD PRESSURE DURING \\ HEMODIALYSIS IN PATIENTS WITH END- STAGE RENAL DISEASE}

Objectives of the study: To study the factors related to changes of blood pressure during hemodialysis in patients with ESRD. Research methodology: cross-sectional descriptive study. Results: Survey 714 times of dialysis in 119 patients shows that: (1) $20,2 \%$ of dialysis had hypertension and $15,8 \%$ of dialysis had hypotension; (2) In the group of patients over 50 years old, the rate of hypotension was $57,5 \%$ and the rate of hypertension was $57,3 \%$, that is higher than the group of patients $<50$ years old; the group of patients who gained more than $3 \mathrm{~kg}$ between 2 dialysis times had the highest rate of hypotension that was 53,9\%; the group of patients on hemodialysis with ultrafiltration rate $>750$ $\mathrm{ml} / \mathrm{h}$, the concentration of blood ure and creatinine are high and the concentration of blood albumin is low that have a higher risk of hypotension while on dialysis $(p<0.05)$. Conclusion: The variation of blood pressure during dialysis in patients with ESRD is related to: age $>50$ years, increased body weight by 